\title{
Research Paper: Evaluation of the Opinion of Patients With Multiple Sclerosis on the Outcomes of Catching COVID-19 and Its Effects on the MS Symptoms
}

\author{
Nasim Rezaeimanesh $^{1} \odot$, Mohammad Ali Sahraian' ${ }^{1} \odot$, Abdorreza Naser Moghadasi ${ }^{{ }^{*}}$
}

1. Multiple Sclerosis Research Center, Neuroscience Institute, Tehran University of Medical Sciences, Tehran, Iran.

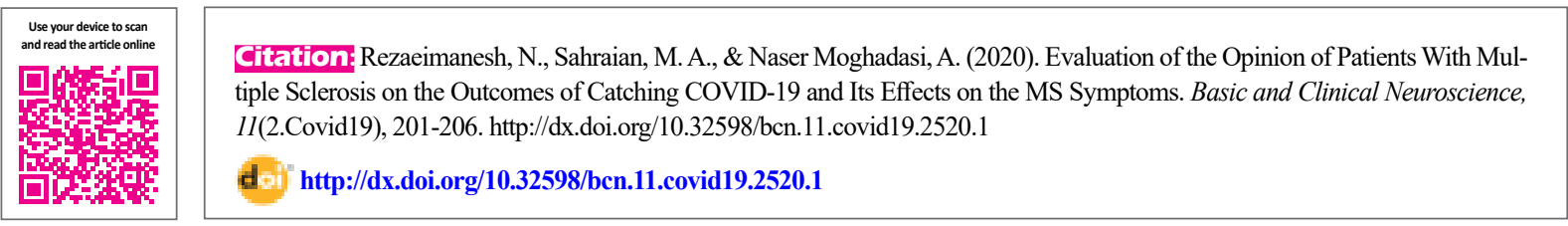

() $0(3)$

Article info:

Received: 11 Apr 2020

First Revision: 12 Apr 2020

Accepted: 15 Apr 2020

Available Online: 20 Apr 2020

Keywords:

Multiple Sclerosis, Coronavirus

Disease 2019 (COVID-19),

Outcome, Concerns

\section{A B S T RA C T}

Introduction: To assess the opinion of patients with Multiple Sclerosis (MS) on the outcomes of COVID-19 (coronavirus disease 2019) and its effects on MS symptoms if they catch coronavirus. A cross-sectional study was performed.

Methods: Considering the study objectives, a questionnaire was designed and prepared as a Google Form for MS patients for one week.

Results: A total of 148 MS patients with an average age of 35.73 years completed the questionnaire. The most important concern of the participants was "a high prevalence of COVID-19" following by the "MS symptoms worsening". Many participants (35\%) believed that, if they catch COVID-19 they will be cured. However, the treatment will take more time for them in comparison with the general population. About $39.8 \%$ of the patients stated that COVID-19 infection does not affect the MS symptom, but others noted that, it can cause relapse $(30.8 \%)$ or worsen MS symptoms $(29.3 \%)$.

Conclusion: This study revealed that MS patients are more anxious about the effects of COVID-19 on their underlying disease rather than the infection itself.

\section{* Corresponding Author:}

Abdorreza Naser Moghadasi, MD.

Address: Multiple Sclerosis Research Center, Neuroscience Institute, Tehran University of Medical Sciences, Tehran, Iran

Tel: +98 (911) 3811334

E-mail: abdorrezamoghadasi@gmail.com 


\section{Highlights}

- This study evaluated the opinion of patients with MS on the outcomes of COVID-19 and its effects on MS symptoms.

- The most important concern of the participants was "a high prevalence of COVID-19" following by the "MS symptoms worsening".

- This study revealed that MS patients are anxious about the effects of COVID-19 on their underlying disease.

\section{Plain Language Summary}

Due to the ongoing pandemic of COVID-19 and the increased risk of infection in MS patients, we conducted a crosssectional study to assess the major concerns of MS patients in this regard. A total of 148 MS patients with a mean age of 35.73 years were enrolled in this study and completed the designed form. Although death was thought to be the main concern of COVID-19 patients, our study showed that the high prevalence of the disease and the worsening of MS disease due to COVID-19 infection were the major concerns of MS patients. According to the answers to the third question, more than $60 \%$ of patients believed that COVID-19 could induce MS attack or worsen their disease process. Relapsing-remitting MS patients typically experience the stable state of their disease and were more worried about the high prevalence of COVID-19, while the most concern of primary progressive MS participants was the worsening of MS disease due to COVID-19 infection, maybe due to progressive nature of their underlying disease. They were mostly concerned about the impact of COVID-19 on MS rather than the disease itself.

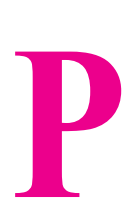

\section{Introduction}

atients with Multiple Sclerosis (MS) have an elevated risk of catching an infection in comparison with the general population. Besides, MS patients experience more severe infection with a higher rate of mortality and these infections are the major cause of death in MS patients (Celius, 2017). So, they need to receive more attention in the case of infection.

The increased risk of infection in MS patients could be attributed both to disease-modifying treatments and disability. In patients with advanced MS, infections and fever could result in worsening disease symptoms, and all the worsening may become irreversible. Also, the most common infections among MS patients are urinary tract infections and pneumonia (Celius, 2017; Williamson \& Berger, 2015).

In December 2019, a large number of patients with viral pneumonia were identified in Wuhan, China (Peeri et al, 2020). In January 2020, the novel coronavirus 2019 (COVID-19) was recognized by the Chinese Center for Disease Control and Prevention (CDC) (Chen et al., 2020). The virus spread very fast to all parts of the world, and the World Health Organization (WHO) announced a "Public Health Emergency of International Concern (PHEIC)" on February 1, 2020 (Peeri et al, 2020).
COVID-19 infection may cause severe pneumonia and pulmonary edema, or it can be developed to Acute Respiratory Distress Syndrome (ARDS), multiple organ dysfunction, or even death (Peeri et al, 2020).

\section{Methods}

Due to the ongoing pandemic of COVID-19 and the increased risk of infection in MS patients, we conducted a cross-sectional study to assess the major concerns of MS patients in this regard. For this purpose, we designed a primary questionnaire, which was completed by two MS patients to evaluate the intelligibility of questions. Then, those questions that were not intelligible were edited. Next, the questionnaire was sent to four expert neurologists in MS and one epidemiologist, and their comments on the content of questions were applied. The final version of the questionnaire was formatted as a Google Form and the link was made available for MS patients in social networks for one week.

\section{Results}

A total of 148 MS patients with a mean age of 35.73 years completed the form. About $86.7 \%$ of the participants were women. Of 124 persons who answered the type of MS question, 93 subjects (75\%) had RelapsingRemitting MS (RRMS), 18 (14.51\%) had Primary Progressive MS (PPMS), 11 (8.87\%) had secondary pro- 
gressive MS (SPMS), and others had Clinically Isolated Syndrome (CIS). The average disease duration of the participants was 4.07 years.

The main concern of the patients was the "high prevalence of COVID-19", which 57 individuals (41.6\%) from 137 total answers reported it. The next concerns were the "worsening MS symptoms due to coronavirus infection" mentioned by 49 patients $(35.8 \%)$, "death caused by COVID-19" reported by 43 patients (31.4\%), "more complication of coronavirus in patients with MS" chosen by 40 patients $(29.2 \%)$, and "quarantine during coronavirus outbreak" reported by 31 participants $(22.2 \%)$ (Figure 1).

Of $140 \mathrm{MS}$ patients who completed the question of "what will be the result if you catch new coronavirus?" $49(35 \%)$ answered "I will be cured, but the treatment will take more time for me", 38 (27.1\%) subjects selected the answer "I will be cured and my disease process will be similar to the others", 36 (25.7\%) declared that "catching COVID-19 will result in my death", and $17(12.1 \%)$ selected the option "I will be cured, but the complications of COVID-19 infection will affect me".

Many participants (39.8\%) believed that "COVID-19 infection does not affect MS symptoms". But $30.8 \%$ of them believed that "COVID-19 may cause relapse", and 29.3\% selected the answer "COVID-19 infection may worsen MS symptoms".
It should be noted that there was no association between the answers and participants' age, sex, or type of disease in any question. Table 1 presents the study participants' answers to each question based on different types of MS. Answers of "the most concerns of patients with Multiple Sclerosis (MS) on coronavirus" $(\mathrm{P}=0.05)$ and "What will be the result if you catch new coronavirus?" $(\mathrm{P}=0.001)$ questions were statistically different between MS types groups, but there was no significant difference in the answer to " the effect of coronavirus on MS" question" $(\mathrm{P}=0.084)$.

Many RRMS participants (42.1\%) were worried about "the high prevalence of coronavirus" while the most concern of PPMS patients (50.0\%) was "MS worsening by catching coronavirus". Many RRMS (33.7\%) and SPMS $(63.6 \%)$ patients thought that they would eventually be cured, but the treatment would take more time for them, while $55.6 \%$ of PPMS patients thought that they would be cured and their disease process would be similar to the general population.

\section{Discussion}

Although death was thought to be the main concern of COVID-19 patients, our study showed that the high prevalence of the disease and the worsening of MS disease due to COVID-19 infection were the major concerns of MS patients. RRMS patients typically experience the stable state of their disease and were more worried about the high prevalence of COVID-19, while the most concern of PPMS participants was the worsen-

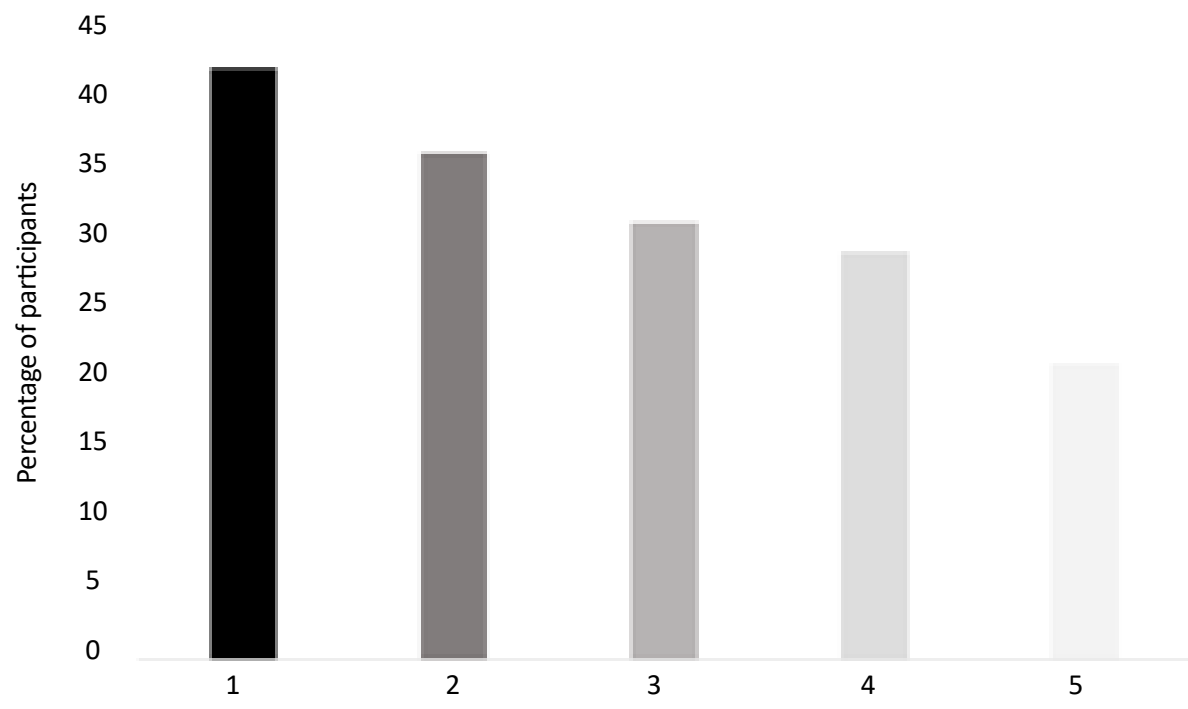

Figure 1. The most concerns of the patients with multiple sclerosis (MS) about coronavirus

1. The high prevalence of coronavirus; 2. MS worsening by catching coronavirus; 3. Death because of coronavirus infection; 4 . More complication of coronavirus in patients with MS; 5 . Quarantine during coronavirus outbreak

* Each bar shows what percentages of participants selected that concern as one of their concerns about coronavirus. 
Table 1. The association between MS type and the participants' answers to each question

\begin{tabular}{|c|c|c|c|c|c|c|}
\hline \multirow{3}{*}{\multicolumn{2}{|c|}{ Question }} & \multicolumn{4}{|c|}{ Multiple Sclerosis (MS) Types } & \multirow{3}{*}{ P* } \\
\hline & & & No. (\%) & & & \\
\hline & & RRMS & PPMS & SPMS & CIS & \\
\hline \multirow{5}{*}{$\begin{array}{l}\text { The most concerns of the } \\
\text { patients with Multiple } \\
\text { Sclerosis (MS) about } \\
\text { coronavirus }\end{array}$} & $\begin{array}{l}\text { The high prevalence of } \\
\text { coronavirus }\end{array}$ & $40(42.1)$ & $4(22.2)$ & $3(27.3)$ & $2(100)$ & \multirow{5}{*}{0.05} \\
\hline & $\begin{array}{l}\text { More complication of } \\
\text { coronavirus in patients with MS }\end{array}$ & $16(16.8)$ & $3(16.7)$ & $3(27.3)$ & $0(0)$ & \\
\hline & $\begin{array}{l}\text { Quarantine during coronavirus } \\
\text { outbreak }\end{array}$ & $11(11.6)$ & $1(5.6 \%)$ & $1(9.1)$ & $0(0)$ & \\
\hline & $\begin{array}{l}\text { Death because of } \\
\text { coronavirus infection }\end{array}$ & 17 (17.9) & $1(5.6)$ & $1(9.1)$ & $0(0)$ & \\
\hline & $\begin{array}{l}\text { MS worsening by } \\
\text { catching coronavirus }\end{array}$ & $11(11.6)$ & $9(50.0)$ & $3(27.3 \%)$ & $0(0)$ & \\
\hline \multirow{4}{*}{$\begin{array}{l}\text { What will be the results if } \\
\text { you catch new } \\
\text { coronavirus? }\end{array}$} & $\begin{array}{l}\text { I will be cured and my disease } \\
\text { process will be similar } \\
\text { to the others. }\end{array}$ & $16(16.3)$ & $10(55.6)$ & $3(27.3)$ & $2(100)$ & \multirow{4}{*}{0.001} \\
\hline & $\begin{array}{l}\text { I will be cured, but the treat- } \\
\text { ment will take more } \\
\text { time for me. }\end{array}$ & $33(33.7)$ & $6(33.3)$ & $7(63.6)$ & $0(0)$ & \\
\hline & $\begin{array}{l}\text { I will be cured, but the } \\
\text { complications of COVID-19 } \\
\text { infection will affect me. }\end{array}$ & 17 (17.3) & $0(0)$ & $0(0)$ & $0(0)$ & \\
\hline & $\begin{array}{l}\text { Catching COVID-19 will result } \\
\text { in my death. }\end{array}$ & $32(32.7)$ & $3(11.1)$ & $1(9.1)$ & $0(0)$ & \\
\hline \multirow{3}{*}{$\begin{array}{l}\text { The effect of } \\
\text { coronavirus on MS }\end{array}$} & $\begin{array}{l}\text { COVID-19 infection does not } \\
\text { affect MS symptoms. }\end{array}$ & $38(39.2)$ & $3(23.1)$ & $4(40.0)$ & $1(50.0)$ & \multirow{3}{*}{0.84} \\
\hline & COVID-19 may cause relapse. & $30(30.9)$ & $5(38.5)$ & $4(40.0)$ & $1(50.0)$ & \\
\hline & $\begin{array}{l}\text { COVID-19 infection may cause } \\
\text { MS symptoms worsening. }\end{array}$ & 29 (29.9) & $5(38.5)$ & $2(20.0)$ & $0(0)$ & \\
\hline
\end{tabular}

MS: Multiple Sclerosis; RRMS: Relapsing-Remitting MS; PPMS: Primary Progressive MS; SPMS: Secondary Progressive MS; CIS: Clinically Isolated Syndrome

* The Chi-squared test

ing of MS disease due to COVID-19 infection, maybe due to progressive nature of their underlying disease. They were mostly concerned about the impact of COVID-19 on MS rather than the disease itself. About $35 \%$ of the patients, in response to our question about the outcomes of COVID-19, answered that they would be treated, but the duration of treatment would be longer for them compared with normal people.

These answers may be due to the correct attitude towards the COVID-19 pandemic. Most cases of COVID-19 are asymptomatic or have mild symptoms, and only $0.25 \%$ to $3 \%$ die (Wilson, Kvalsvig, Barnard, \& Baker, 2020). Therefore, other effects of this pandemic may be more important to the general public. However, for MS patients, this may be due to the impact of this infection on their underlying disease. Infections can exacerbate earlier symptoms and cause a relapse in MS patients. Although no study has been published on the impact of COVID-19 disease on the exacerbation of MS, this is possible as a viral infection.

A few studies reviewed the COVID-19 infection in MS patients. An Italian investigation reported $232 \mathrm{MS}$ patients with COVID-19 infection. A total of 222 (96\%) had mild symptoms, $4(2 \%)$ had severe symptoms and $6(3 \%)$ were in critical classification, 5 of them died. Twenty-one participants had received a 5-day course of 
methylprednisolone during the last 3 months of study attendance (Sormani, 2020).

So, this concern is quite evident in MS patients. According to the answers to the third question, more than $60 \%$ of patients believed that COVID-19 could induce MS attack or worsen their disease process. Although this study was conducted on a small number of patients, it revealed the patients' great concern about their underlying disease even during the pandemic. This reasonably accurate belief indicates that patients have a good understanding of MS and COVID-19 that is consistent with the results of a recent study in Iran on the knowledge of MS patients about COVID-19 infection. Almost 90\% of participants were aware of the pandemic stage of the COVID-19 and the importance of using masks and gloves for protection. All of them knew the high person to person transmission rate of infection and $73 \%$ of them followed the rules of quarantine (Sahraian, Gheini, Rezaeimanesh, Ghajarzadeh, Naser Moghadasi, 2020).

Although the study did not take the patients' education level into account, this level of awareness was not out of mind, assuming the patients' mean age and their probable information.

Our study has some limitations. Not all of the MS patients could access the Internet and this is the main limitation of this study. The cognitive and education level of the patients could influence their concern about COVID-19 infection and its effects on MS. So, we suggest that these items be evaluated in future studies.

\section{Ethical Considerations}

\section{Compliance with ethical guidelines}

The project protocol has been confirmed with ethic code in ethical committee of Tehran University of Medical Sciences (IR.TUMS.VCR.REC.1399.145).

\section{Funding}

This research did not receive any specific grant from funding agencies in the public, commercial, or not-forprofit sectors.

\section{Authors' contributions}

Data analysis, data collection, drafting the manuscript and approving the final format of the manuscript: Nasim Rezaeimanesh; Drafting the manuscript and approving the final format of the manuscript: Mohammad Ali Sahraian; Hypothesis, supervision, data collection, drafting the manuscript and approving the final format of the manuscript: Abdorreza Naser Moghadasi.

\section{Conflict of interest}

The authors declared no conflict of interest.

\section{References}

Celius, E. (2017). Infections in patients with multiple sclerosis: Implications for disease-modifying therapy. Acta Neurologica Scandinavica, 136, 34-6. [DOI:10.1111/ane.12835] [PMID]

Williamson, E. M., Berger, J. R. (2015). Infection risk in patients on multiple sclerosis therapeutics. CNS Drugs, 29(3), 229-44. [DOI:10.1007/s40263-015-0226-2] [PMID]

Peeri, N. C., Shrestha, N., Rahman, M. S., Zaki, R., Tan, Z., \& Bibi, S., et al. (2020). The SARS, MERS and novel Coronavirus (COVID-19) epidemics, the newest and biggest global health threats: what lessons have we learned? International Journal of Epidemiology. [Published Online] [DOI:10.1093/ije/dyaa033] [PMID] [PMCID]

Chen, N., Zhou, M., Dong, X., Qu, J., Gong, F., Han, Y., et al. (2020). Epidemiological and clinical characteristics of 99 cases of 2019 novel coronavirus pneumonia in Wuhan, China: A descriptive study. The Lancet, 395(10223), 507-13. [DOI:10.1016/ S0140-6736(20)30211-7]

Wilson, N., Kvalsvig, A., Barnard, L. T., Baker, M. (2020). CaseFatality Risk Estimates for COVID-19 Calculated by Using a Lag Time for Fatality. Emerging Infectious Diseases, 26(6), 1339441. [DOI:10.3201/eid2606.200320]

Sormani, M. P. (2020). An Italian programme for COVID-19 infection in multiple sclerosis. The Lancet Neurology, 19(6):481-2. [DOI:10.1016/S1474-4422(20)30147-2]

Sahraian, M. A., Gheini, M. R., Rezaeimanesh, N., Ghajarzadeh, M., \& Naser Moghadasi, A. (2020). Knowledge regarding COVID-19 pandemic in patients with Multiple Sclerosis (MS): A report from Iran. Multiple Sclerosis and Related Disorders, 42, 102193. [DOI:10.1016/j.msard.2020.102193] [PMID] [PMCID] 
This Page Intentionally Left Blank 